\title{
The Role of Advanced Practice Registered Nurses in the Completion of Physician Orders for Life-Sustaining Treatment
}

\author{
Sophia A. Hayes, BS, Dana Zive, MPH, Betty Ferrell, PhD, MA, FAAN, FPCN, and Susan W. Tolle, MD ${ }^{4}$
}

\begin{abstract}
Background: The Physician Orders for Life-Sustaining Treatment (POLST) Paradigm records advance care planning for patients with advanced illness or frailty as actionable medical records. The National POLST Paradigm Task Force recommends that physicians, advanced practice registered nurses (APRNs), and physician assistants (PAs) be permitted to execute POLST forms.

Objective: To investigate the percentage of Oregon POLST forms signed by APRNs, and examine the obstacles faced by states attempting to allow APRNs to sign POLST forms.

Design: Cross-sectional.

Setting/subjects: 226,101 Oregon POLST Registry forms from 2010 to 2015.

Measurements: POLST forms in the Oregon Registry were matched with signer type (MD, DO, APRN, PA). Results: 226,101 POLST forms have been added to the Oregon POLST Registry from 2010 to 2015: $85.3 \%$ of forms were signed by a physician, $10.9 \%$ of forms were signed by an APRN, and $3.8 \%$ of forms were signed by a PA. From 2010 to 2015, the overall percentage of POLST forms signed by an APRN has increased from $9.0 \%$ in 2010 to $11.9 \%$ in 2015. Physicians are authorized signers in all 19 states with endorsed POLST Paradigm programs; 16 of these states also authorize APRN signature, and 3 states (LA, NY, and GA) allow only physicians to sign.

Conclusions: More than 10\% of Oregon POLST forms are signed by APRNs. Given the need for timely POLST form completion, ideally by a member of the interdisciplinary team who knows the patient's preferences best, these data support authorizing APRNs to complete POLST forms.
\end{abstract}

Keywords: advanced care planning; advanced practice registered nurse; end-of-life care; POLST; scope of practice

\section{Introduction}

$\mathbf{I}_{\mathbf{s}}$ NDIVIDUALS FACING ADVANCED ILLNESSES have differing goals for care, and they often reach out to healthcare professionals for help in matching their goals with available medical interventions. ${ }^{1,2}$ The Physician Orders for LifeSustaining Treatment (POLST) paradigm has emerged as a powerful tool to guide conversations about end-of-life treatments with patients and to preserve patient preferences as medical orders. ${ }^{3-30}$ As of May of 2016, 47 states are either developing or have already endorsed POLST programs. Each state differs slightly in the structure and policies that characterize their POLST programs. Of note, variation exists between states with respect to the type of healthcare

\footnotetext{
${ }^{1}$ School of Medicine, Oregon Health \& Science University, Portland, Oregon.

${ }^{2}$ Center for Policy and Research in Emergency Medicine, Oregon Health \& Science University, Portland, Oregon.

${ }^{3}$ Division of Nursing Research and Education, Department of Population Sciences, Beckman Research Institute of City of Hope, Duarte, California.

${ }^{4}$ Division of General Internal Medicine and Geriatrics, Center for Ethics in Health Care, Oregon Health \& Science University, Portland, Oregon.

Accepted September 19, 2016.

(C) Sophia A. Hayes et al., 2017; Published by Mary Ann Liebert, Inc. This Open Access article is distributed under the terms of the Creative Commons Attribution Noncommercial License (http://creativecommons.org/licenses/by-nc/4.0/) which permits any noncommercial use, distribution, and reproduction in any medium, provided the original author(s) and the source are credited.
} 
professionals who are permitted to sign and execute POLST forms. States differ in the terminology used to describe their programs. However, most endorsed states use either "physician orders" or "medical orders" in the name of their program, which may not be considered inclusive of all signing healthcare professionals. ${ }^{31}$

Although states retain autonomy in determining the details of their programs, the National POLST Paradigm Task Force (NPPTF) recommends that physicians, advanced practice registered nurses (APRNs), and physician assistants (PAs) be permitted to execute POLST forms. ${ }^{31}$ Some states have become more inclusive as their programs mature. For example, CA and WV passed legislation in 2016 allowing APRNs to execute POLST orders. However, of the 19 states with programs endorsed by the NPPTF in 2016, 3 allow only physicians to sign POLST orders. ${ }^{31}$ These three states (NY, LA, and GA) and the growing number of developing state programs will face the decision as to whether or when they will permit APRNs to sign POLST forms in the future.

For patients facing an advanced illness, timely access to end-of-life care and counseling can have significant bearing on their quality of life and place of death. ${ }^{27,28,30,32} \mathrm{Re}-$ membering that POLST orders are completed a median of six weeks before death, restricting the work force available to assist in form completion may add to delays and unwanted treatments. ${ }^{27}$ APRNs are recommended as a means to increase access to patient-centered services and care. ${ }^{29,33-36}$ This recommendation is supported by new Centers for Medicare and Medicaid Services (CMS) billing codes to be used by both physicians and APRNs as of January of 2016 for goals of care counseling reimbursement. ${ }^{37}$ This brief report uses data from the Oregon POLST Registry to explore the role that APRNs can play, as part of the patient's interdisciplinary care team, in this important element of end-of-life care.

\section{Materials and Methods}

\section{Study setting}

The study included data from the Oregon POLST Registry, a state-wide electronic registry of Oregon POLST forms. These data were collected under quality assurance and quality improvement for the Oregon POLST Registry and were not submitted for IRB review. No patient data were accessed, thereby protecting all patient confidentiality. Upon voluntary completion of a POLST form, the signing healthcare professional or his or her designee is mandated to submit the form to the Registry unless a patient specifically opts out. POLST forms in the Registry from 2010 to 2015 were analyzed for the authorizing healthcare professional discipline. The primary aim was to assess the percentage of forms that were signed by APRNs each year as compared with either physicians or PAs.

\section{Population}

The study included 226,101 Oregon POLST Registry forms that were entered from 2010 to 2015.

\section{Variables}

The variable analyzed from the Oregon POLST Registry was the type of healthcare professional who signed each
POLST form as well as the percentage completed by each professional discipline during each year of the study.

\section{Data analysis}

The data were analyzed using descriptive statistics to determine the number and percentages of completed POLST forms by the professional signing the forms.

\section{Results}

From 2010 to $2015,226,101$ forms were added to the Oregon POLST Registry. Of those, $10.9 \%$, or 24,620 , forms were signed by APRNs, and $85.3 \%$ were signed by physicians (the remaining $3.8 \%$ were signed by PAs). Figure 1 shows the percentage of POLST forms signed by APRNs for each year from 2010 to 2015. The percentage of POLST forms signed by APRNs in Oregon increased from $9.0 \%$ to $11.4 \%$ between 2010 and 2012 of registry operation and has remained relatively flat during the remaining four years.

Table 1 depicts states with endorsed POLST programs that allow APRNs and physicians to sign POLST forms, or only allow physicians to sign POLST forms. Out of the 19 states with endorsed programs, 3 (NY, LA, and GA) do not allow APRNs to sign POLST forms.

\section{Discussion}

End-of-life and palliative care are interdisciplinary endeavors. Patient-centered treatment often requires the expertise of primary and specialist care. A palliative care clinician provides such specialist care. Goals of care conversations need to take place and should be initiated by the healthcare professional who knows the patient best. ${ }^{38} \mathrm{~A}$ relationship with continuity is the ideal context for discussing goals of care that may lead to POLST completion in seriously ill patients. APRNs may have that relationship with a patient more than other clinicians. There is general agreement, though, that the number of physicians and APRNs trained in hospice and palliative medicine is grossly inadequate to meet the needs of the growing population of aging Americans. ${ }^{39,40}$

Primary care and palliative care are increasingly team based and interdisciplinary. APRNs work both collaboratively with and independent of physicians in many settings and play an integral role in the care of patients with advanced illness. $^{28,29,33-36}$ Our data suggest that in Oregon, a state that has permitted APRNs to sign POLST forms since 2001, the percentage of POLST forms signed by APRNs is slowly increasing. These results suggest that APRNs are well positioned to initiate goals of care conversations because they know the patients best, are invited to take the lead by the healthcare team, or they have advanced training in palliative care or geriatrics. As APRNs become a significant and recognized part of the interdisciplinary cancer care team, APRNs are positioned to take on a greater role in advance care planning. Research has shown that APRNs have positive attitudes but moderate knowledge and limited experience in advance care planning. ${ }^{41,42}$ States that allow APRNs and physicians to sign POLST forms honor the role of both professional groups in preserving patient preferences.

Access is not consistent across all endorsed states. State licensure and practice laws are a barrier to APRNs' practicing to the fullest extent of their education and training, specifically 


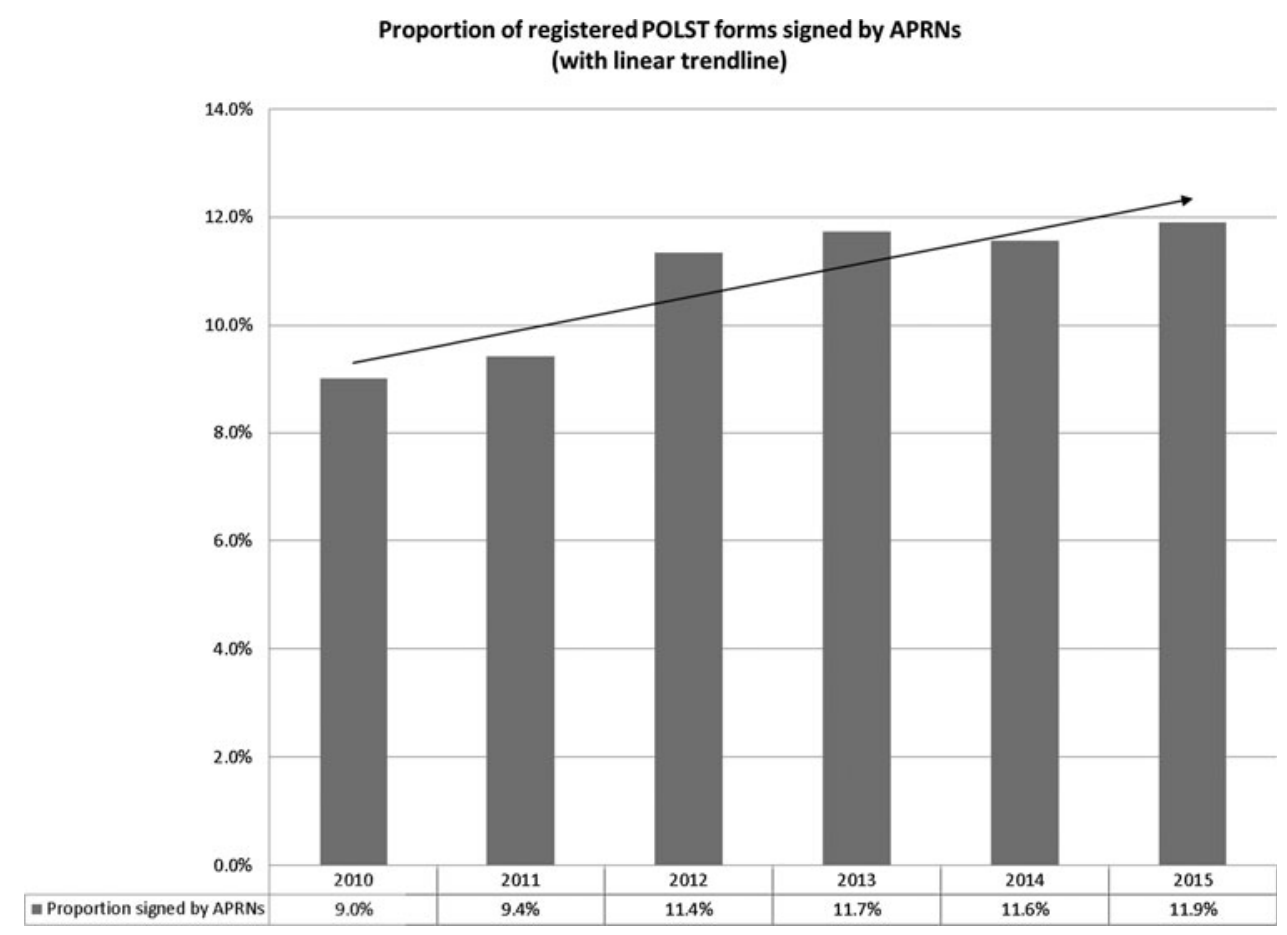

FIG. 1. Proportion of registered physician orders for life-sustaining treatment forms signed by advanced practice registered nurses from 2010 to 2015 .

with regard to POLST forms. ${ }^{43,44}$ Communication with POLST program leaders from states that do not allow APRNs to sign revealed that lack of support from state medical associations represents a major roadblock in approving more inclusive POLST policies. In contrast, California recently passed legislation in 2016 allowing APRNs to sign POLST

Table 1. Health Professional Disciplines Authorized to Sign Physician Orders FOR LifE-Sustaining TREATMENT Forms

\begin{tabular}{lll}
\hline $\begin{array}{l}\text { APRNs signing } \\
\text { before 2016 }\end{array}$ & $\begin{array}{c}\text { APRNs signing } \\
\text { authorized } \\
\text { in 2016 }\end{array}$ & $\begin{array}{c}\text { Physician } \\
\text { signing only }\end{array}$ \\
\hline Colorado & California & $\begin{array}{c}\text { Georgia } \\
\text { Hawaii }\end{array}$ \\
Idaho & West Virginia & Louisiana \\
Iowa & & New York \\
Maine & & \\
Montana & & \\
North Carolina & \\
Oregon & \\
Pennsylvania & \\
Tennessee & \\
Utah & \\
Virginia & \\
Washington & \\
Wisconsin & \\
\hline
\end{tabular}

Only established POLST Programs endorsed before August 2016 are included in this analysis. All states that allowed APRNs to sign POLST forms also allow physicians and physician assistants to sign. Developing programs are not included.

APRNs, advanced practice registered nurse; POLST, physician orders for life-sustaining treatment. forms, with support from the California Medical Association (CMA). The CMA recognized that authorizing APRNs to sign POLST forms facilitated completion because timely access to a physician can sometimes be difficult to obtain. ${ }^{45}$

Allowing APRNs, as part of the team of interprofessional healthcare professionals, to sign POLST forms is an important step in providing timely, patient-centered care. At its core, the POLST paradigm exists to facilitate and honor goals of care conversations between patients and the healthcare professionals who know them best. For some patients, that professional might be a physician, for others it might be an APRN. It is important, not only from a political and economic perspective but also from a humanistic perspective, that POLST policies recognize and honor the range of professionals who are best positioned to counsel patients and document their wishes.

\section{Limitations}

This was a retrospective analysis of available data and was not intended to quantify the relationship between the proportion of POLST forms signed by APRNs and the quality of end-of-life care. This was not a random sample, as individuals who choose to have a POLST form may be different from the general population.

\section{Conclusions}

Eleven percent of POLST forms in the Oregon Registry are signed by APRNs. There are an increasing number of states with endorsed POLST programs that are allowing APRNs to sign POLST forms. This trend suggests that APRNs are performing a vital and growing role in advance care planning including POLST completion. 


\section{Acknowledgment}

The authors thank Valerie Jimenez, Oregon POLST Coordinator, for her technical support in the completion of this article.

\section{Author Disclosure Statement}

Ms. Hayes reports no financial interests or potential conflicts of interest. Ms. Zive reports salary support as the Director of the Oregon POLST Registry, which operates at OHSU under contract with the Oregon Health Authority. She serves as a Senior Scholar with the Center for Ethics in Health Care at OHSU, as well as the Oregon POLST Task Force Research Liaison. She is a member of the NPPTF Research Committee and is currently the technology advisor for the NPPTF. Dr. Ferrell reports no financial interests or potential conflicts of interest. Dr. Tolle reports grants from California HealthCare Foundation, The Retirement Research Foundation, and the Archstone Foundation, during the conduct of the study. Dr. Tolle chairs the NPPTF Research Committee, the Oregon POLST Task Force, and directs the OHSU Center for Ethics in Health Care, which serves as the administrative home of both the National POLST Paradigm and Oregon POLST Programs. The OHSU Center for Ethics in Health Care does not accept funding from healthcare industry sources.

\section{References}

1. Vig EK, Davenport NA, Pearlman RA: Good deaths, bad deaths, and preferences for the end of life: A qualitative study of geriatric outpatients. J Am Geriatr Soc 2002;50: 1541-1548.

2. McNeil C: A good death. J Palliat Care 1998;14:5-6.

3. Moss AH, Zive DM, Falkenstine EC, et al.: Physician orders for life-sustaining treatment medical intervention orders and in-hospital death rates: Comparable patterns in two state registries. J Am Geriatr Soc 2016;64:1793-1741.

4. Jennings LA, Zingmond D, Louie R, et al.: Use of the physician orders for life-sustaining treatment among California nursing home residents. J Gen Intern Med 2016;31: 1119-1126.

5. Dunn PM, Schmidt TA, Carley MM, et al.: A method to communicate patient preferences about medically indicated life-sustaining treatment in the out-of-hospital setting. J Am Geriatr Soc 1996;44:785-791.

6. Tolle SW, Tilden VP, Nelson CA, Dunn PM: A prospective study of the efficacy of the physician order form for lifesustaining treatment. J Am Geriatr Soc 1998;46:1097-1102.

7. Lee MA, Brummel-Smith K, Meyer J, et al.: Physician orders for life-sustaining treatment (POLST): Outcomes in a PACE program. J Am Geriatr Soc 2000;48:1219-1225.

8. Schmidt TA, Zive D, Fromme EK, et al.: Physician orders for life-sustaining treatment (POLST): Lessons learned from analysis of Oregon POLST registry. Resuscitation 2014;85: 480-485.

9. Hickman SE, Tolle SW, Brummel-Smith K, et al.: Use of the physician orders for life-sustaining treatment program in Oregon nursing facilities: Beyond resuscitation status. J Am Geriatr Soc 2004;52:1424-1429.

10. Schmidt TA, Hickman SE, Tolle SW, et al.: The physician orders for life-sustaining treatment program: Oregon emergency medical technicians' practical experiences and attitudes. J Am Geriatr Soc 2004;52:1430-1434.
11. Richardson DK, Fromme E, Zive D, et al.: Concordance of out-of-hospital and emergency department cardiac arrest resuscitation with documented end-of-life choices in Oregon. Ann Emerg Med 2014;63:375-383.

12. Schmidt TA, Olszewski EA, Zive D, et al.: The Oregon physician orders for life-sustaining treatment registry: A preliminary study of emergency medical services utilization. J Emerg Med 2013;44:796-805.

13. Hickman SE, Nelson CA, Perrin NA, et al.: A comparison of methods to communicate treatment preferences in nursing facilities: Traditional practice versus the physician orders for life-sustaining treatment program. J Am Geriatr Soc 2010;58:1241-1248.

14. Hickman SE, Nelson CA, Moss AH, et al.: Use of the physician orders for life-sustaining treatment for scope of treatment (POLST) paradigm program in the hospice setting. J Palliat Med 2009;12:133-141.

15. Hickman SE, Nelson CA, Moss AH, et al.: The consistency between treatments provided to nursing facility residents and orders on the physician orders for life-sustaining treatment form. J Am Geriatr Soc 2011:59:2091-2099.

16. Hickman SE, Nelson CA, Smith-Howell E, et al.: Use of the physician orders for life-sustaining treatment program for patients being discharged from the hospital to the nursing facility. J Palliat Med 2014;17:43-49.

17. Hammes BJ, Rooney BL, Gundrum MS, et al.: The POLST program: A retrospective review of the demographics of use and outcomes in one community where advance directives are prevalent. J Palliat Med 2012;15:1.

18. Araw AC, Araw AM, Pekmezarius R, et al.: Medical orders for life-sustaining treatment: Is it time yet? Palliat Support Care 2014;12:101-105.

19. Bomba PA, Orem K: Lessons learned from New York's community approach to advance care planning and MOLST. Ann Palliat Med 2015;4:10-21.

20. Vo H, Pekmezaris R, Guzik H, et al.: Knowledge and attitudes of health care workers regarding MOLST implementation in long-term care facilities. Geriatr Nurs 2011; 32:58-62.

21. Caprio AJ, Rollins VP, Roberts E: Health care professionals' perceptions and use of the Medical Orders for Scope of Treatment (MOST) form in North Carolina nursing homes. J Am Med Dir Assoc 2012;13:162-168.

22. Meyers JL, Moore C, McGrory A, et al.: Orders for lifesustaining treatment form: Honoring end-of-life directives for nursing home residents. J Am Geriatr Soc 2002;50:829835.

23. Fromme EK, Zive D, Schmidt Terri, et al.: Association between physician orders for life-sustaining treatment for scope of treatment and in-hospital death in Oregon. J Am Geriatr Soc 2014;62:1246-1251.

24. Institute of Medicine of the National Academies: Dying in America: Improving Quality and Honoring Individual Preferences Near the End of Life. Report of Key Findings and Recommendations, 2014.

25. Oregon POLST Program: Oregon POLST Program Webpage [on-line]. www.or.polst.org. (Last accessed July 21, 2016).

26. Fromme EK, Zive D, Schmidt TA, et al.: POLST registry do-not-resuscitate orders and other patient treatment preferences. JAMA 2012;307:34-35.

27. Zive DM, Fromme EK, Schmidt TA, et al.: Timing of POLST form completion by cause of death. J Pain Symptom Manage 2015;50:650-658. 
28. American Academy of Nursing: Advance Care Planning as an Urgent Public Health Concern. 2013. www.aannet.org/ policy-brief-advance-care-planning-as-an-urgent-publichealth-concern-2013 (Last accessed October 14, 2016).

29. National Quality Forum, A National Framework and Preferred Practices for Palliative and Hospice Care Quality: A Consensus Report. 2006. www.qualityforum.org/Publications/ 2006/12/A_National_Framework_and_Preferred_Practices_ for_Palliative_and_Hospice_Care_Quality.aspx

30. Pedraza SL, Culp S, et al.: POST forms more than advance directives associated with out-of-hospital death: Insights from a state registry. J Pain Symptom Manage 2016;51: 240-246.

31. The National POLST Paradigm Taskforce: National POLST Paradigm Webpage [on-line]. www.polst.org. (Last accessed July 21, 2016).

32. Teno JM, Gozalo PL, Bynum JP, et al.: Change in end-oflife care for Medicare beneficiaries: Site of death, place of care, and health care transitions in 2000, 2005, and 2009. JAMA 2009;309;470-477.

33. Heinle R, McNulty J, Hebert RS: Nurse practitioners and the growth of palliative medicine. Am J Hosp Palliat Med 2014;31:287-291.

34. Hospice and Palliative Nurses Association: HPNA position statement: Value of the advanced practice registered nurse in palliative care. http://hpna.advancingexpertcare.org/wpcontent/uploads/2015/08/Value-of-the-Advanced-PracticeRegistered-Nurse-in-Palliative-Care.pdf. (Last accessed July 21, 2016).

35. Fairman JA, et al.: Broadening the scope of nursing practice. N Engl J Med 2011;364:193-196.

36. Institute of Medicine: The Future of Nursing: Leading Change, Advancing Health. Washington, DC: National Academies Press, 2010.

37. Centers for Medicare and Medicaid Services: Proposed Policy, Payment, and Quality Provisions Changes to the Medicare Physician Fee Schedule for Calendar Year 2016. www.cms.gov/Newsroom/MediaReleaseDatabase/Factsheets/2015-Fact-sheets-items/2015-10-30-2.html. (Last accessed July 21, 16).
38. Tolle SW, Back AL, Meier DE: Clinical decisions. Endof-Life Advance Directive. N Engl J Med 2015;372:667670.

39. Lupu D: Estimate of current hospice and palliative medicine physician workforce shortage. J Pain Symptom Manage 2010;40:899-911.

40. Ortman JM, Velkoff VA, Hogan H: An Aging Population: The Older Population in the United States. U.S. Census Bureau Current Population Reports, 2014.

41. Zhou G, Stoltzfus JC, Houldin AD, et al.: Knowledge, attitudes, and practice behaviors of oncology advanced practice nurses regarding advanced care planning for patients with cancer. Oncol Nurs Forum 2010;37:E400-E410.

42. Gesme DH, Wiseman M: Advance care planning with your patients. Oncol Pract 2011;7:e42-e44.

43. Hain D, Fleck LM: Barriers to NP Practice that Impact Healthcare Redesign. www.nursingworld.org/MainMenu Categories/ANAMarketplace/ANAPeri odicals/OJIN/Table ofContents/Vol-19-2014/No2-May-2014/Barriers-to-NPPractice.html (Last accessed October 14, 2016).

44. Institute of Medicine: The Future of Nursing: Leading Change, Advancing Health. www.nationalacademies.org/ hmd/Reports/2010/The-Future-of-Nursing-Leading-ChangeAdvancing-Health.aspx (Last accessed October 14, 2016).

45. California Assembly Bill 637. www.leginfo.ca.gov/pub/1516/bill/asm/ab_0601-0650/ab_637_cfa_20150608_145614_ sen_comm.html (Last accessed October 14, 2016).

Address correspondence to:

Susan W. Tolle, MD

Division of General Internal Medicine and Geriatrics Center for Ethics in Health Care Oregon Health \& Science University

UHN-86

3181 SW Sam Jackson Park Road Portland, OR 97239

E-mail: tolles@ohsu.edu 